Research Article

\title{
Study of Radial Vibration Impact on Friction and Torque of Rotary Drill String
}

\author{
Zifeng Li (D), Chaoyue Zhang, Wenming Ren, and Jianwei Ma \\ Petroleum Engineering Institute, Yanshan University, Qinhuangdao 066004, China \\ Correspondence should be addressed to Zifeng Li; zfli@ysu.edu.cn
}

Received 2 May 2020; Revised 17 June 2020; Accepted 30 June 2020; Published 24 July 2020

Academic Editor: Qilong Xue

Copyright (c) 2020 Zifeng Li et al. This is an open access article distributed under the Creative Commons Attribution License, which permits unrestricted use, distribution, and reproduction in any medium, provided the original work is properly cited.

\begin{abstract}
During extended-reach well drilling, the torque of a rotary drill string is too large in the horizontal section, which results in the failure of the drill string. The effect of radial vibration on the friction and torque of the rotary drill string is unclear. In this work, first, the principle of the impact of radial vibration on the friction and torque of the rotary drill string in the horizontal section is analysed. Then, joints with an elliptical outer edge of the section are designed, which can generate low-amplitude vibration as the drill string rotates owing to the interaction with the wellbore wall. The radial vibration characteristics can be tuned by changing the major to minor radius ratio of the ellipse. A self-developed experimental device was designed to test the performance of tools with reduced friction and torque. The drill string torque with different penetration rates, rotation speeds, and ratios of the major radius to minor radius of the ellipse were systematically studied. The experimental results show that the average and the maximum amplitudes of the torque fluctuation first decrease to the lowest value and then increase with the increase of the ratio. When the ratio reaches 1.065 , the average and the maximum amplitudes of the torque fluctuation evidently reduce; therefore, a joint with a ratio of 1.065 can effectively reduce frictional torque. The average torque reduces when the penetration rate and rotation speed decrease. At rotation speeds of 45 and $60 \mathrm{r} / \mathrm{min}$, the maximum amplitude of torque fluctuation increases first and then decreases with an increase in penetration rate, and it reaches a maximum value at a penetration rate of $22.5 \mathrm{~m} / \mathrm{h}$. The fundamental frequency of torque fluctuation is almost linearly related to rotation speed, which is irrelevant to the penetration rate and the ratio of major to minor radius of the ellipse.
\end{abstract}

\section{Introduction}

Extended-reach wells have been widely applied in the exploration of unconventional oil and gas reservoirs. During the drilling process in the horizontal section, the drill string lies on the bottom of the borehole wall by its gravity, and the friction caused by interaction between the drill string and the borehole wall is large because of the long horizontal section in extended-reach wells. It is difficult for the drill string to transmit torque, and the large torque results in the failure of the drill string. Therefore, good control of the friction and torque is critical to the success of the drilling operation $[1,2]$. Engineering practice shows that there are three effective measures to reduce the friction and torque of the drill string: (1) improving wellbore environments [3], (2) using mechanical tools [4-10], and (3) optimizing engineering parameters such as bottom hole assemblies, drilling fluid performance, and conducting short trips, by monitoring or predicting the friction coefficient at different depths [11-14]. The most efficient method is using mechanical tools.

Many studies have focused on the vibration to reduce the friction and torque of the drill string; however, most of them focused on the axial vibration $[7,8,15-22]$, and only a few studies about the impact of radial vibration on the friction and torque of rotary drill string have been reported. Ouyang et al. [9] developed a turbine-type two-way vibration drag reduction tool that applied eccentric ring rotation to cause radial vibration and water hammer effects to enable axial vibration. This tool can control the exciting force by changing the eccentricity mass. Li [10] developed a radial vibration torsion reduction tool powered by drilling fluid. The field experiment showed that the tool can improve the transfer of drilling weight on the bit. Zhang et al. [23] analysed the impact of amplitude and frequency of the 
exciting force on the friction coefficient of plane friction pairs between the steel and rock plate by experiments. Ren [24] reported that the drill pipe friction reduction joints with an elliptical outer edge of the section can generate lowamplitude vibration as the drill string rotates. However, the effect of radial vibration on the friction and torque of the rotary drill string is not clear.

In this work, the principle of the radial vibration impact on the friction and torque of the rotary drill string is analysed. At the same time, the instantaneous torques of the rotary drilling are measured with different experimental conditions, including the ratio of major radius to minor radius of the joint elliptical section $\left(R_{a / b}\right)$, penetration rate, and rotation speed, which have major impacts on the radial vibration characteristics. The experimental results support the theoretical analysis, providing guidance to study the friction and torque reduction of the rotary drill string by radial vibration.

\section{Theoretical Analysis}

During drilling, the torque on the drill string is caused by the viscous force of the drilling fluid and the sliding friction between the drill string and wellbore [14]:

$$
M(t)=M_{h}(t)+M_{n}(t),
$$

where $M(t)$ is the torque on the drill string, $M_{h}(t)$ is the frictional torque, and $M_{n}(t)$ is the torque generated by the viscous force of the drilling fluid.

Therefore, through reducing the frictional torque $M_{h}(t)$, the torque on the drill string $M(t)$ can be effectively reduced:

$$
M_{h}(t)=R_{0} F_{f}(t),
$$

where $R_{0}$ is the external radius of the drill string and $F_{f}(t)$ is the tangential component of sliding friction between the drill string and wellbore:

$$
F_{f}(t)=f_{t} F_{N}(t)
$$

where $F_{N}(t)$ is the contact force between the drill string and wellbore and $f_{t}$ is the tangential component of the sliding coefficient.

Because of the interaction between the joint with an elliptical outer edge of section and wellbore wall, it generates low-amplitude forced radial vibration as the drill string rotates, and the vibration frequency is associated with the rotation speed of the drill string. The contact force between the drill string and wellbore $F_{N}(t)$ is an instantaneous force, which changes over time, and is related to the radial vibration characteristics. When the drill string leaves the wellbore wall, $F_{N}(t)=0$. At the same time, $F_{f}(t)$ changes with $F_{N}(t)$, thereby further influencing $M_{h}(t)$. Therefore, $M_{h}(t)$ can be influenced by the radial vibration. Because it is difficult to measure $F_{N}(t)$, the torque is measured by a selfdeveloped experimental device, which is designed to test the performance of tools with reducing friction and torque. From the analysis of the experimental results, the effect of the radial vibration on the frictional torque of the rotary drill string is researched in detail.

\section{Experimental Device, Method, and Conditions}

3.1. Experimental Device. Figure 1 shows the experimental device to test the performance of tools with reducing friction and torque [25]. The device is mainly composed of the base, inner rod rotation part, outer cylinder vertical motion part, control and data acquisition system, and other elements. This device can simulate the motion of the rotary drill string with joints in the wellbore, and the penetration rate and rotation speed can be controlled.

The inner rod rotation part is composed of the main motor, couplings, the inner rod (drill string), and the test tool. The inner rod with the test tool can rotate in the outer cylinder driven by the main motor. The outer cylinder vertical motion part is composed of the outer cylinder (wellbore) and its support, lifting table, feed motor, and sliding table. The outer cylinder goes through linear translational motion on the sliding table driven by the feed motor. In addition, the height of the outer cylinder can be changed by adjusting the lifting table to meet the requirements of different test tools and prevent the motor from having a locked rotor. The main motor and the feed motor are controlled by a computer, the main motor adjusts the rotation speed, and the feed motor adjusts the penetration rate. The torque sensor measures the real-time torque and transfers the data to the computer.

Figure 2 shows the structure of the drill pipe friction reduction joint; $R_{a / b}$ of the joint elliptical section is a key parameter to control the radial vibration, and the section parameters of different joint models are given in Table 1. The drill pipe friction reduction joints are named the 1617 joint, 1618 joint, and 1619 joint according to the value of the minor radius and major radius.

\subsection{Experimental Method}

(1) The test tool is assembled with other elements of the inner-rod rotation part, which should be away from the outer cylinder. At the same time, the slider should stay at one end of the sliding table.

(2) The bottom of the outer cylinder is covered with sand evenly.

(3) The rotation speed of the inner rod is adjusted by the main motor.

(4) The height of the outer cylinder is adjusted and fixed by the lifting table to make the test tool contact the outer cylinder.

(5) The horizontal velocity (i.e., penetration rate) of the outer cylinder is adjusted, and data collection is carried out.

(6) After the experiment, the power supply is turned off, and the outer cylinder is lowered and cleaned.

Afterwards, the measurement results are subjected to fast Fourier transform (FFT), and the time domain signal is converted into a frequency domain signal; thereby, the 


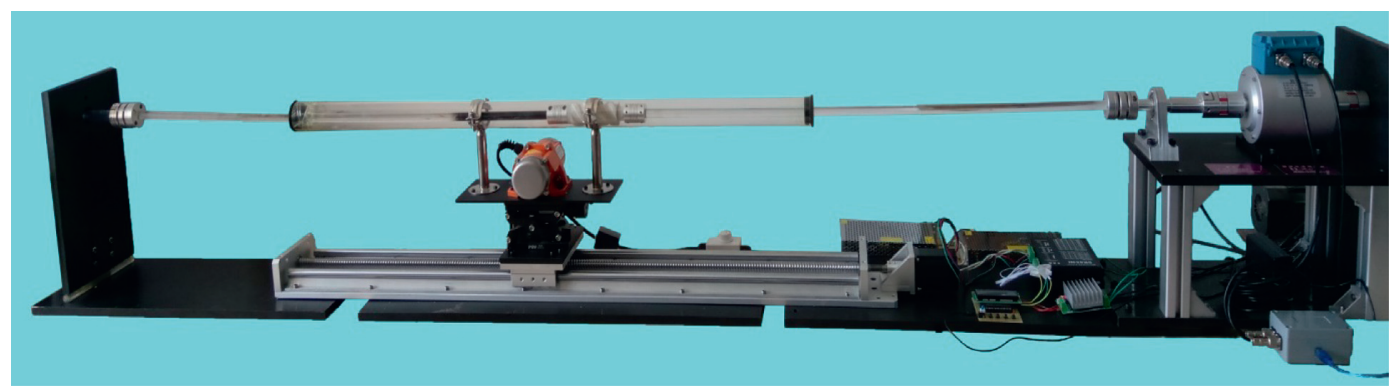

(a)

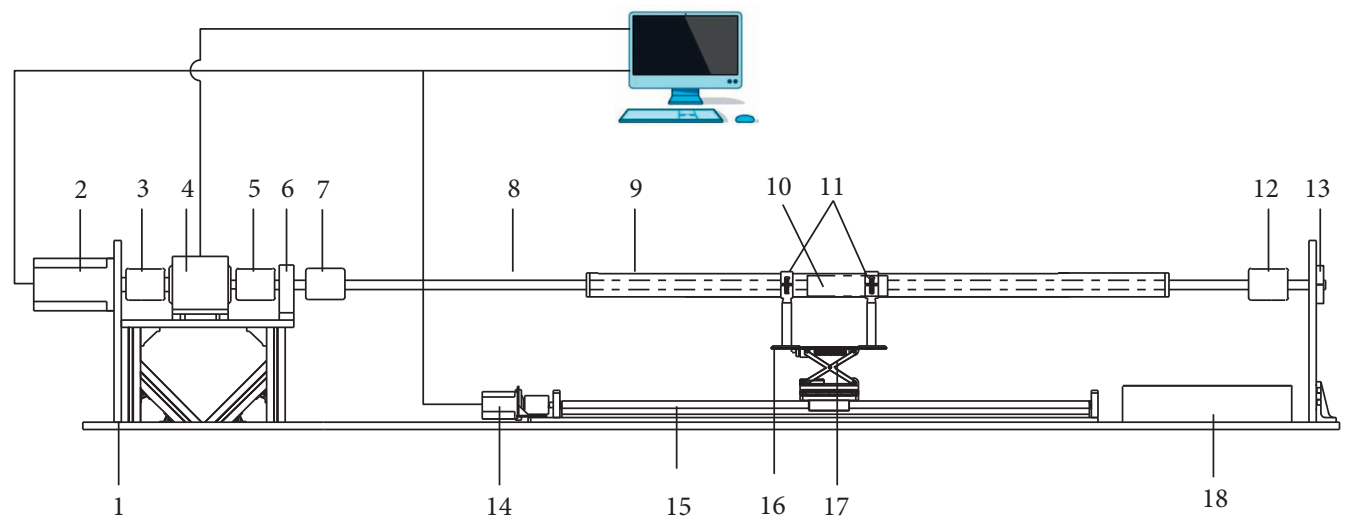

(b)

Figure 1: (a) Photograph of the experimental device used to test the performance of tools. (b) Schematic of the experimental device: (1) base, (2) main motor, (3) coupling A, (4) torque sensor, (5) coupling B, (6) bearing A and its support, (7) resilient coupling A, (8) inner rod (drill string), (9) outer cylinder (wellbore), (10) test tool, (11) support of outer cylinder, (12) resilient coupling B, (13) bearing B, (14) feed motor, (15) sliding table, (16) connection plate, (17) lifting table, (18) fluid container, and (19) computer.
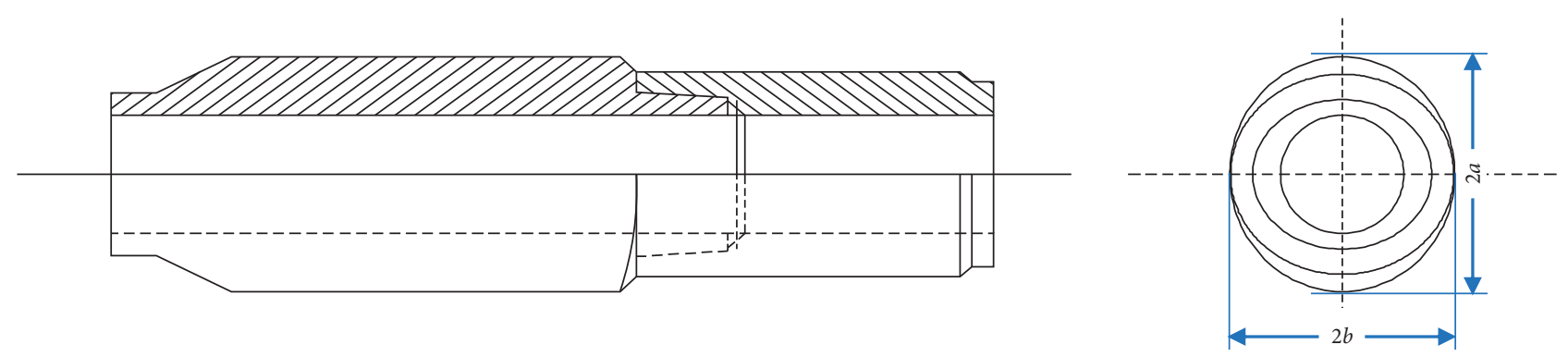

FIGURE 2: Schematic of the drill pipe friction reduction joint.

TABLE 1: Section parameters of different joints models.

\begin{tabular}{|c|c|c|c|c|}
\hline \multirow{2}{*}{\multicolumn{2}{|c|}{ Tool model }} & \multicolumn{3}{|c|}{ Section parameters } \\
\hline & & $\begin{array}{l}\text { Major radius } a \\
\quad\left(\times 10^{-3} \mathrm{~m}\right)\end{array}$ & $\begin{array}{l}\text { Minor radius } b \\
\left(\times 10^{-3} \mathrm{~m}\right)\end{array}$ & $\begin{array}{l}\text { Ratio of major radius to minor radius } \\
\text { of the joint elliptical section } R_{a / b}\end{array}$ \\
\hline Common joint & & 16 & 16 & 1 \\
\hline Drill pipe & 1617 joint & 17 & 16 & 1.0625 \\
\hline Friction & 1618 joint & 18 & 16 & 1.125 \\
\hline Reduction joints & 1619 joint & 19 & 16 & 1.1875 \\
\hline
\end{tabular}




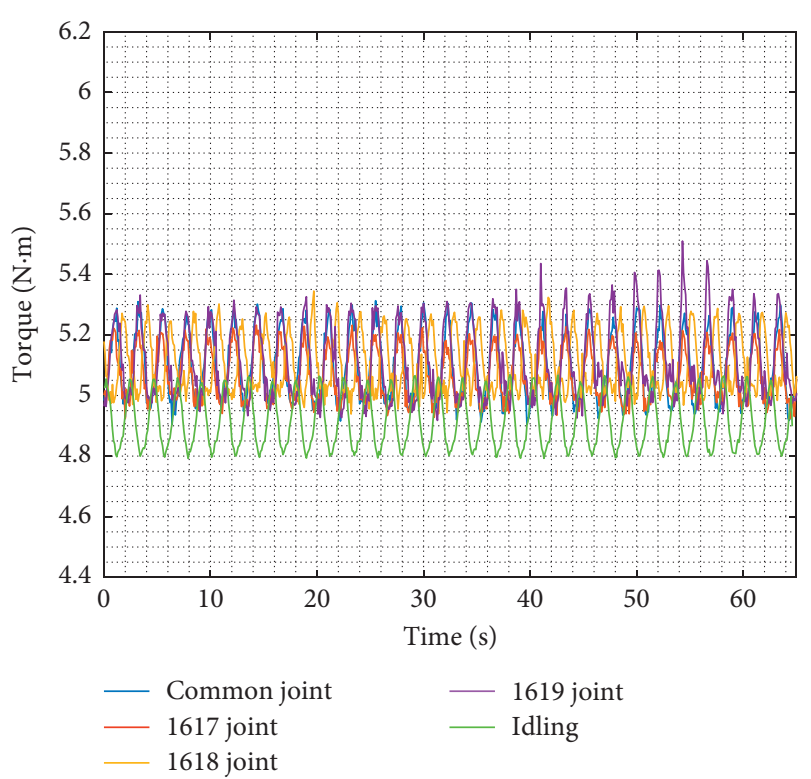

FIgURE 3: Torque-time curves with a rotation speed of $30 \mathrm{r} / \mathrm{min}$ and a penetration rate of $18 \mathrm{~m} / \mathrm{h}$.

amplitude spectrum of torque is obtained. Finally, the changing laws of the torque are analysed.

3.3. Experimental Conditions. The outer cylinder of the experimental device was a grooved acrylic tube, with an inner diameter of $55 \mathrm{~mm}$ and a wall thickness of $2 \mathrm{~mm}$. The torque sensor was a strain-gauge-type torque sensor, with a rated load of $0-10$ N.m and a total error of $\pm 0.5 \%$ F.S. The sliding table was an automatic delicate sliding table, with a stroke of $1000 \mathrm{~mm}$ and a repositioning precision of 0.02 0.03 $\mathrm{mm}$.

\section{Experimental Results and Analysis}

The instantaneous output torque of the motor changed periodically around a certain average value, which was caused by its mechanical structure and the output of the rotor rotary inertia. Therefore, the measured torque fluctuated periodically over time. Figure 3 shows the torquetime curves with a rotation speed of $30 \mathrm{r} / \mathrm{min}$ and a penetration rate of $18 \mathrm{~m} / \mathrm{h}$. The torque fluctuation had a certain periodicity, and the torque fluctuation range was different when using different joints. At the same time, tuning $R_{a / b}$ of the joint could change the radial vibration characteristics, further influencing the torque fluctuation range.

The linear trend of torque-time could be obtained by the detrend function. Figure 4 shows the linear trend of the torque-time curves when the rotation speed was $30 \mathrm{r} / \mathrm{min}$ and the penetration rate was $18 \mathrm{~m} / \mathrm{h}$. The torque was minimum when the main motor was idling (without installing an inner rod and test tool). Compared with the common joint, the torque-time curves with drill pipe friction reduction joints grew faster, which can be attributed to the sand accumulation. During the experiment, the bottom of the outer cylinder was covered with sand evenly to simulate

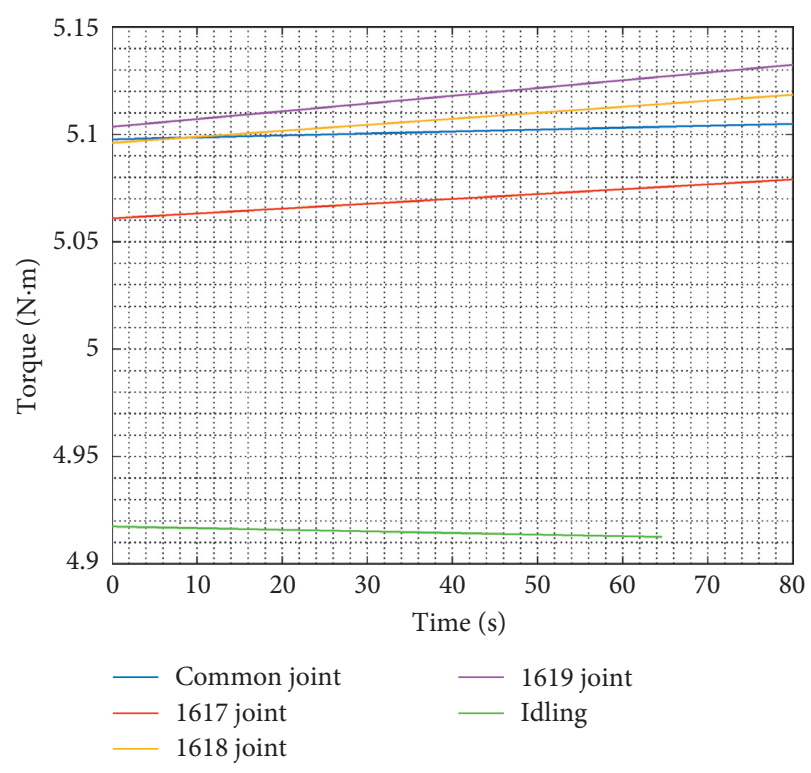

FIGURE 4: Linear trend of torque-time curves with a rotation speed of $30 \mathrm{r} / \mathrm{min}$ and a penetration rate of $18 \mathrm{~m} / \mathrm{h}$.

the real wellbore condition. However, there was no circulation of the drilling fluid. Therefore, when the drill pipe friction reduction joint was moving in the outer cylinder horizontally, a small amount of sand grains gradually accumulated at the front end of the joint, and the formation of sand piles led to the increase of torque. Consequently, the drilling fluid should have a strong carrying capacity when using the drill pipe friction reduction joint.

4.1. Effects of $R_{a / b}$ on Torque. To study the effect of $R_{a / b}$ on torque under different penetration rates and rotation speeds, the torques using joints with different $R_{a / b}(1,1.0625,1.125$, and 1.1875 ) are measured under penetration rates of $18 \mathrm{~m} / \mathrm{h}$, $22.5 \mathrm{~m} / \mathrm{h}$, and $27 \mathrm{~m} / \mathrm{h}$. The experiments were conducted by keeping penetration rate and rotation speed as constant, and the rotation speeds adopted are $30 \mathrm{r} / \mathrm{min}, 45 \mathrm{r} / \mathrm{min}$, and $60 \mathrm{r} /$ $\min$.

With rotation speeds of 30,45 , and $60 \mathrm{r} / \mathrm{min}$ and penetration rates of $18,22.5$, and $27 \mathrm{~m} / \mathrm{h}$, the relationship between the $R_{a / b}$ and the average torque was obtained, as shown in Figure 5. The average torque decreased first and then increased with the increase of $R_{a / b}$ under the three different rotation speeds. The average torque dropped the most with the increase of $R_{a / b}$ under a rotation speed of $30 \mathrm{r} /$ min, as in Figure 5(a), and decreased the least under a rotation speed of $60 \mathrm{r} / \mathrm{min}$, as in Figure 5(c). When $R_{a / b}$ was 1.0625 , the average torque reached its minimum, which was obviously lower than that of the common joint. After that, with the further increase of $R_{a / b}$, the average torque gradually increased. When $R_{a / b}$ reached 1.1875, the average torque was even higher than that of the common joint.

The time domain signal was converted into a frequency domain signal through the FFT of the experimental results, and the amplitude spectrum of the torque was obtained. The amplitude spectra of torque with different joints and the 


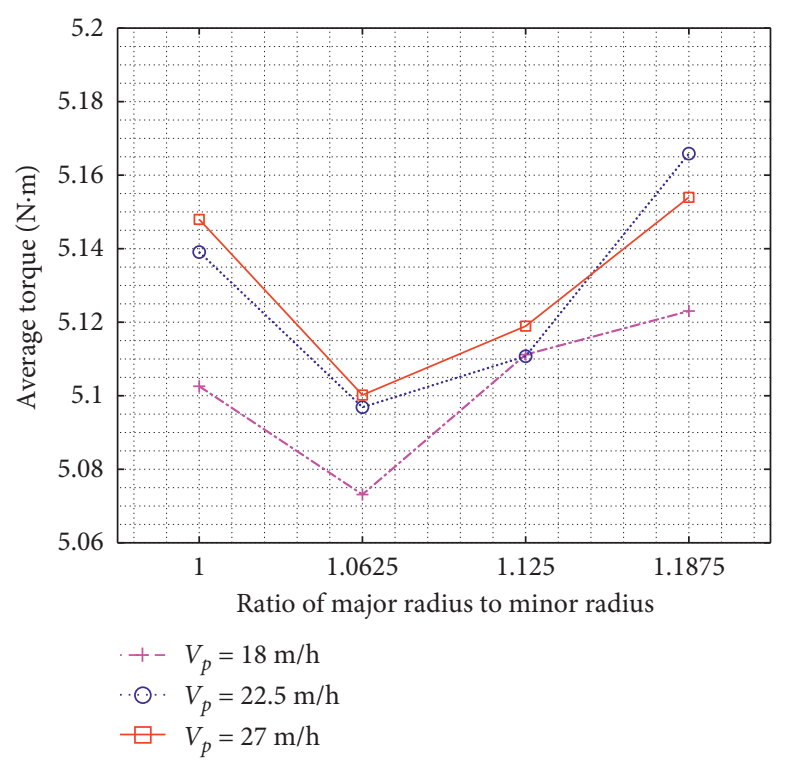

(a)

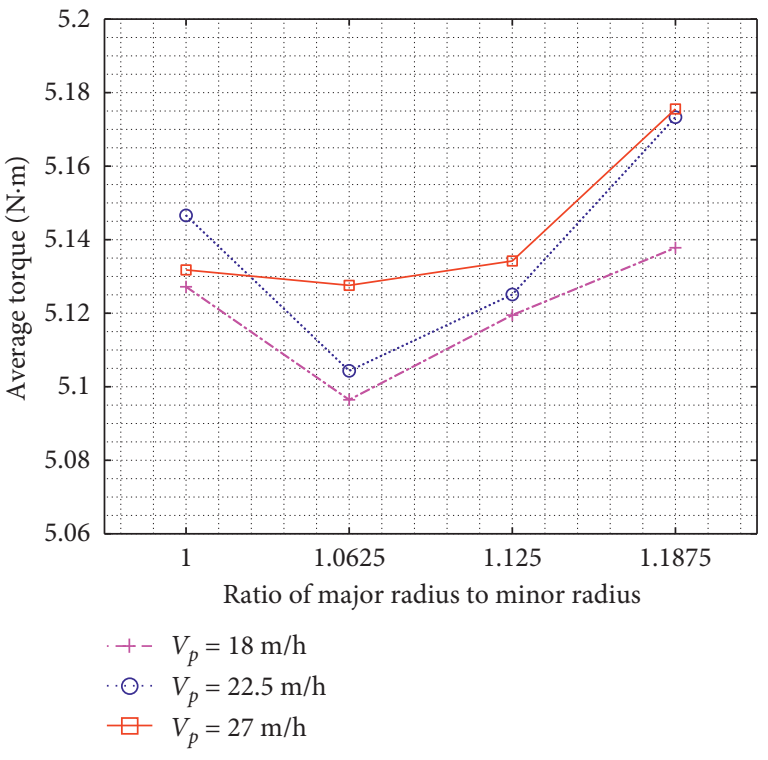

(b)

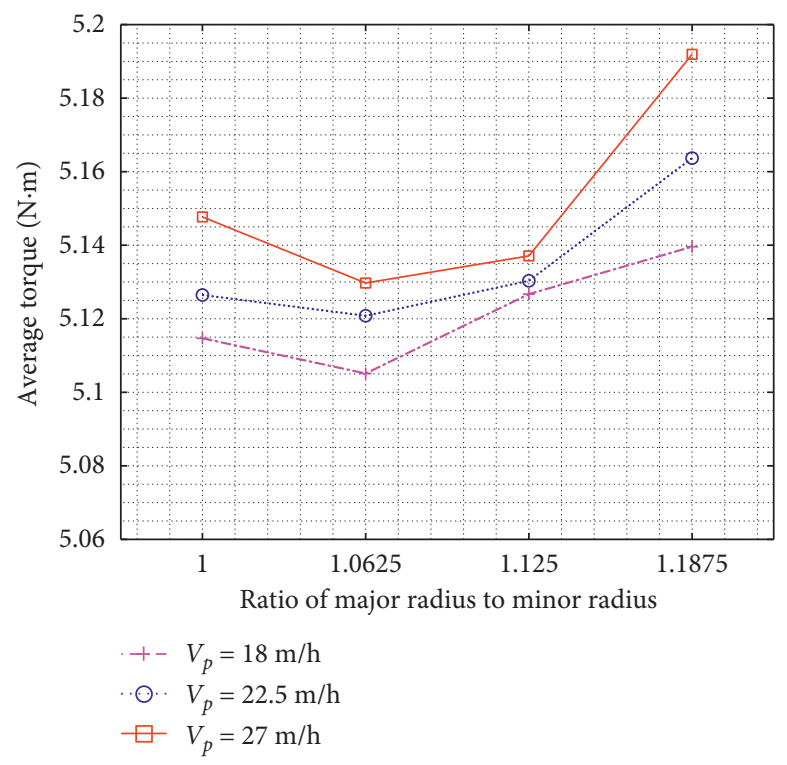

(c)

FIgURE 5: Curves of the average of torque changing with $R_{a / b}$. (a) Rotation speed $V_{r}=30 \mathrm{r} / \mathrm{min}$. (b) Rotation speed $V_{r}=45 \mathrm{r} / \mathrm{min}$. (c) Rotation speed $V_{r}=60 \mathrm{r} / \mathrm{min}$.

main motor idling, when the rotation speed was $30 \mathrm{r} / \mathrm{min}$ and the penetration rate was $18 \mathrm{~m} / \mathrm{h}$, are displayed in Figure 6. The frequency corresponding to the maximum amplitude of torque fluctuation was the fundamental frequency. The maximum amplitudes of the torque fluctuation were different when using different joints, while the fundamental frequency was the same and equal to the fundamental frequency when the main motor was idling. It can be concluded that the fundamental frequency of the torque fluctuation is irrelevant to $R_{a / b}$. Therefore, by tuning the $R_{a / b}$, the amplitudes of drill string radial vibration can be changed without affecting the frequency of the drill string radial vibration. A violent vibration of the drill string makes serious accidents, such as drill string failure and borehole diameter enlargement [26]; thus, it is necessary to minimise the vibration amplitude, that is, to reduce the maximum amplitude of the torque fluctuation.

Figure 7 shows the curves of the maximum amplitude of the torque with different $R_{a / b}$. With the increase of $R_{a / b}$, the maximum amplitude of torque fluctuation decreased first and then increased. It can be clearly seen that the maximum amplitude of torque fluctuation was lower than that of the common joint when $R_{a / b}$ reached 1.0625. With further increase of $R_{a / b}$, the change of maximum amplitude tended to be gentle. When $R_{a / b}$ exceeded 1.125 , the maximum amplitude increased rapidly.

The results indicate that both the average and the maximum amplitude of torque fluctuation can be affected by 


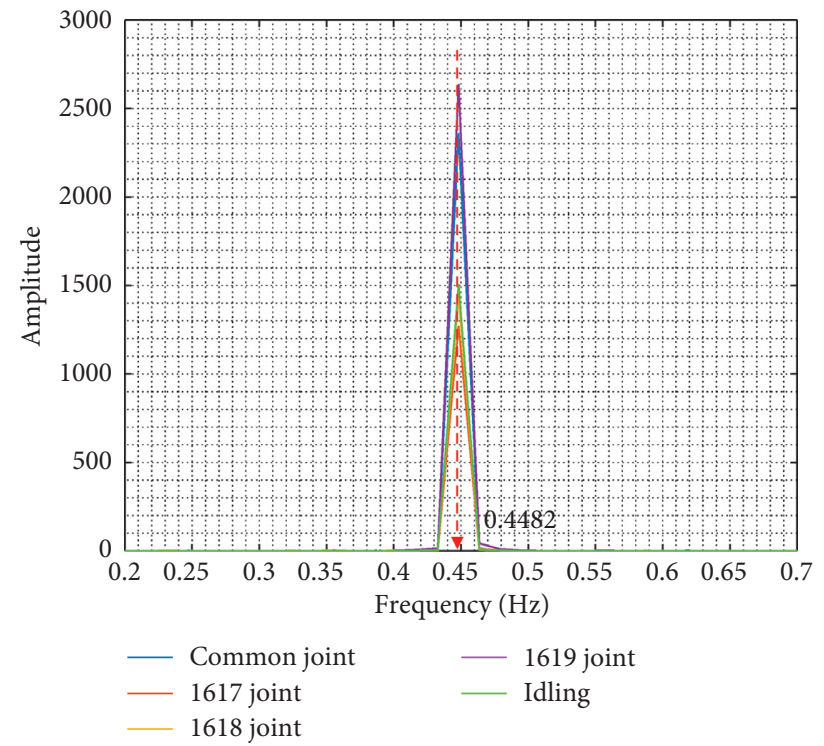

Figure 6: Amplitude spectrum of torque with a rotation speed of $30 \mathrm{r} / \mathrm{min}$ and a penetration rate of $18 \mathrm{~m} / \mathrm{h}$.

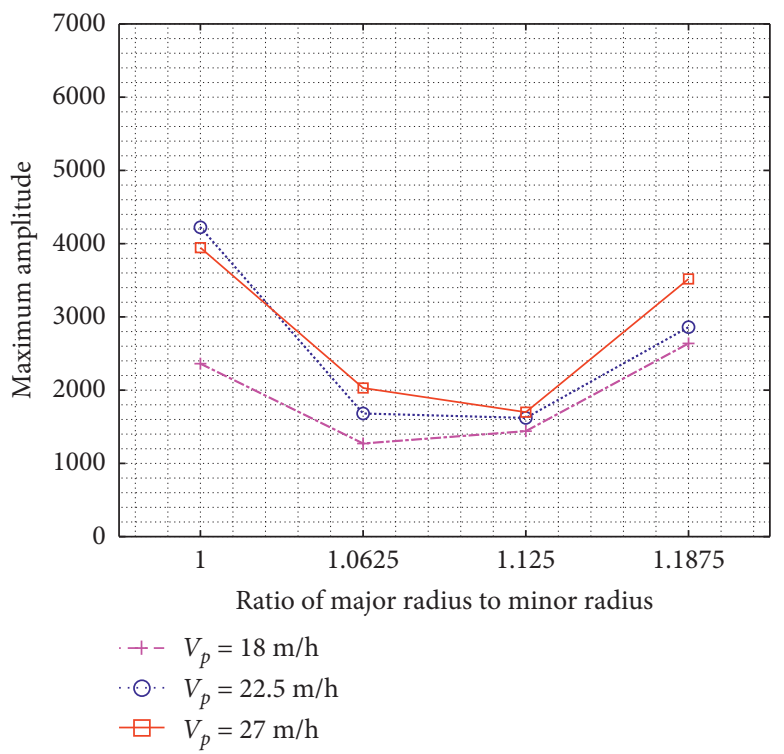

(a)

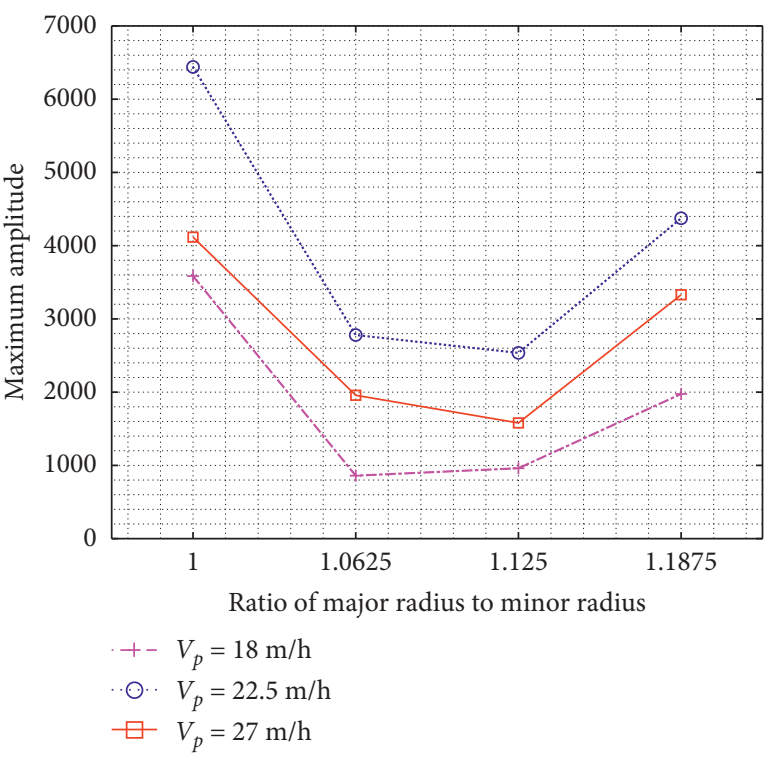

(b)

Figure 7: Continued. 


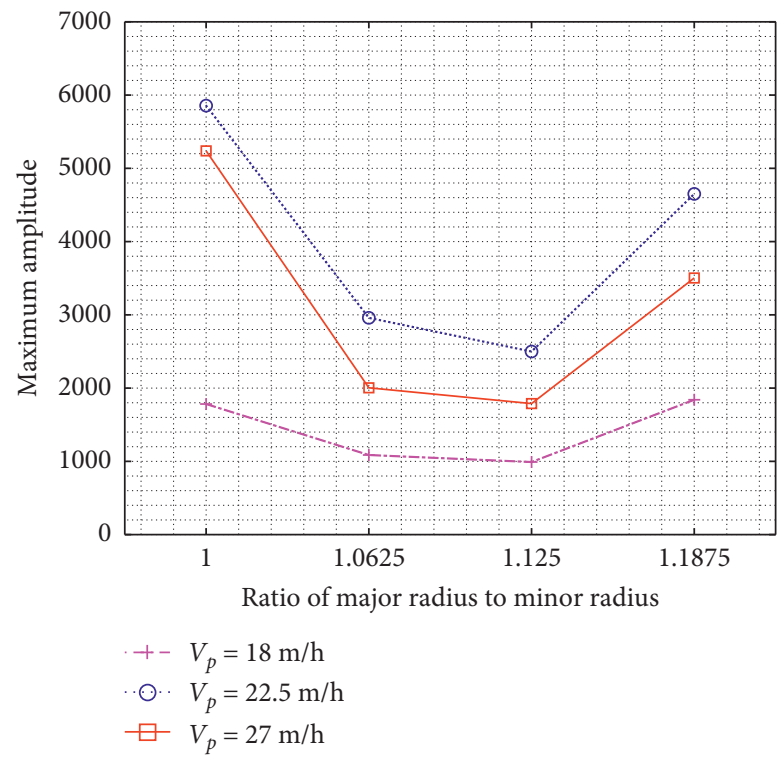

(c)

Figure 7: Curves of the maximum amplitude of the torque changing with $R_{a / b}$. (a) Rotation speed $V r=30 \mathrm{r} / \mathrm{min}$. (b) Rotation speed $V r=45 \mathrm{r} / \mathrm{min}$. (c) Rotation speed $V_{r}=60 \mathrm{r} / \mathrm{min}$.

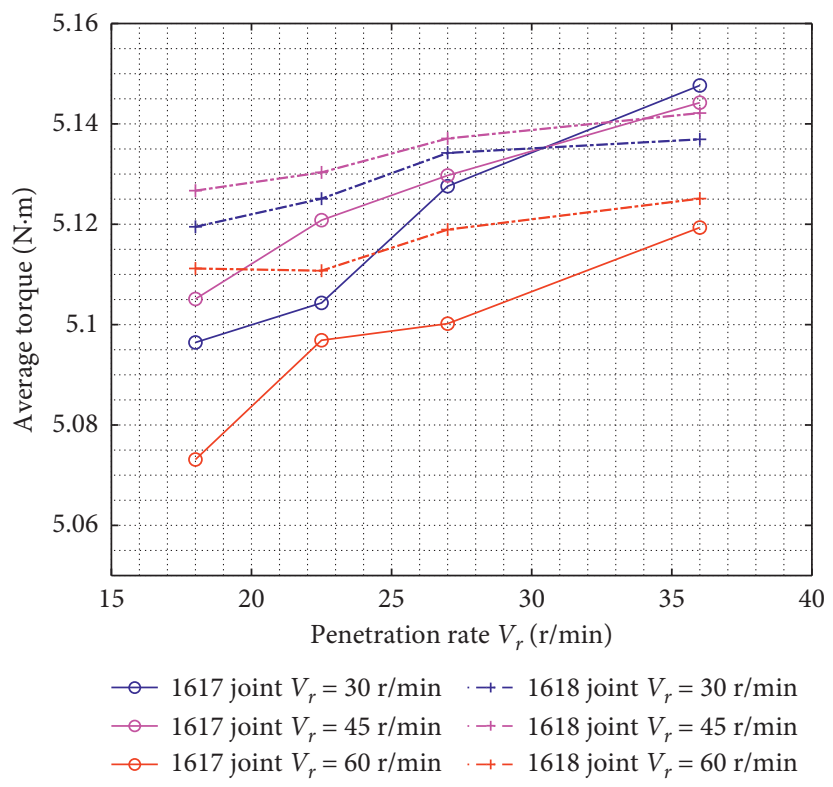

FIGURE 8: Variation of the average of torque changing with penetration rate.

changing $R_{a / b}$ and can be obviously reduced by using 1617 and 1618 joints. In consequence, the 1617 and 1618 joints can effectively reduce the frictional torque of the drill string under experiment condition. Among them, the 1617 joint $\left(R_{a / b}=1.0625\right)$ exhibits the best frictional torque reduction properties with the minimum average value of torque.

4.2. Effects of Penetration Rate on Torque. Based on the above analysis, the 1617 and 1618 joints with frictional torque reduction properties were selected to analyse the effect of penetration rate on the torque of the drill string. With the
1617 (the $R_{a / b}$ is 1.0625) and 1618 (the $R_{a / b}$ is 1.125 ) joints, the torque with different penetration rates $\left(V_{p}=18,22.5,27\right.$, and $36 \mathrm{~m} / \mathrm{h}$ ) was measured under rotation speeds of 30,45 , and $60 \mathrm{r} / \mathrm{min}$. The change rules of the average and the maximum amplitude of torque fluctuation with the penetration rate are shown in Figures 8 and 9.

As shown in Figure 8, the average torque increased gradually with the increase of penetration rate. When using the 1617 joint, the effect of the penetration rate on the average torque was more obvious than that when using the 1618 joint. 


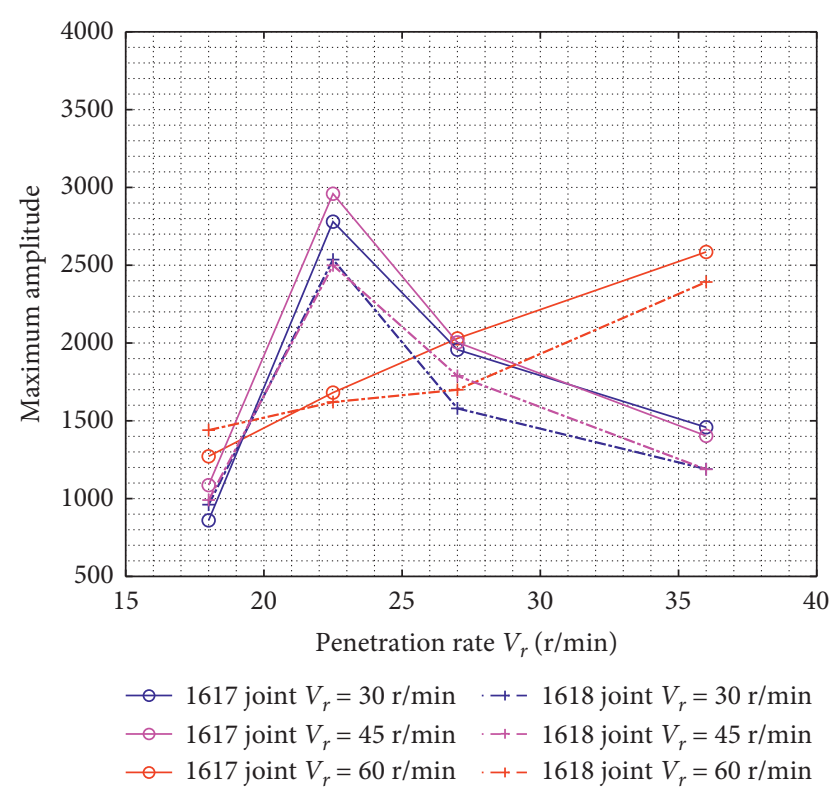

FIGURE 9: Variation of the maximum amplitude of torque fluctuation changing with penetration rate.

With the 1617 and 1618 joints, the variation laws of maximum amplitude of torque fluctuation with penetration rate are similar at the same rotation speed, as shown in Figure 9. The variation of maximum amplitude with penetration rate is closely related to the rotation speed. When the rotation speed was $30 \mathrm{r} / \mathrm{min}$, the maximum amplitude of torque fluctuation increased gradually with the increase of penetration rate. With the rotation speeds of 45 and $60 \mathrm{r} /$ min, the maximum amplitude of torque fluctuation increased first and then decreased with the increase of penetration rate, and the maximum amplitude reached maximum value at a penetration rate of $22.5 \mathrm{~m} / \mathrm{h}$. Therefore, the penetration rate should be as far away as possible from $22.5 \mathrm{~m} / \mathrm{h}$ in the drilling process.

As shown in Figure 10, the amplitude spectra of torque using the 1617 joint were obtained at penetration rates of 18 , 22.5 , and $27 \mathrm{~m} / \mathrm{h}$. The fundamental frequency of torque fluctuation was $0.4482 \mathrm{~Hz}$ at different penetration rates. The maximum amplitudes of the torque fluctuation were different for different penetration rates, but the fundamental frequency was the same. It can be concluded that the fundamental frequency of the torque fluctuation is irrelevant to the penetration rate of drill string. Therefore, through changing the penetration rate, the amplitudes of drill string radial vibration can be changed without affecting the frequency of drill string radial vibration.

4.3. Effects of Rotation Speed on Torque. With the 1617 (the $R_{a / b}$ is 1.0625 ) and 1618 (the $R_{a / b}$ is 1.125 ) joints, the torque with different rotation speeds $\left(V_{r}=30,45,60\right.$, and $\left.90 \mathrm{r} / \mathrm{min}\right)$ was measured under penetration rates of $18,22.5$, and $27 \mathrm{~m} /$ $\mathrm{h}$. The change rules of the average and the maximum amplitude of torque fluctuation with rotation speed are shown in Figures 11 and 12.

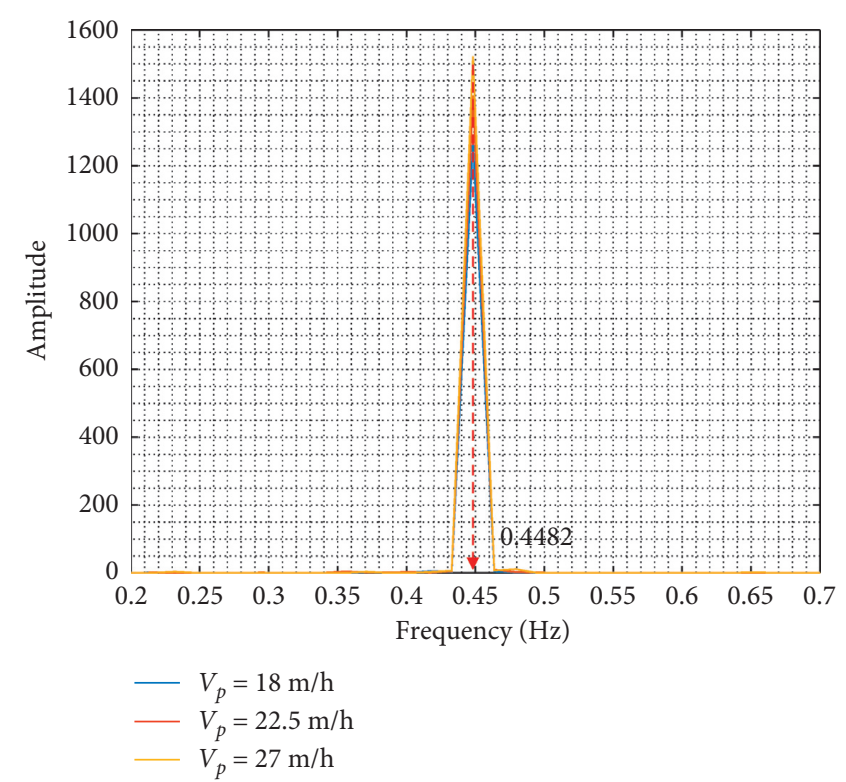

FIgURE 10: Amplitude spectrum of torque at different penetration rates with a rotation speed of $30 \mathrm{r} / \mathrm{min}$ and the 1617 joint.

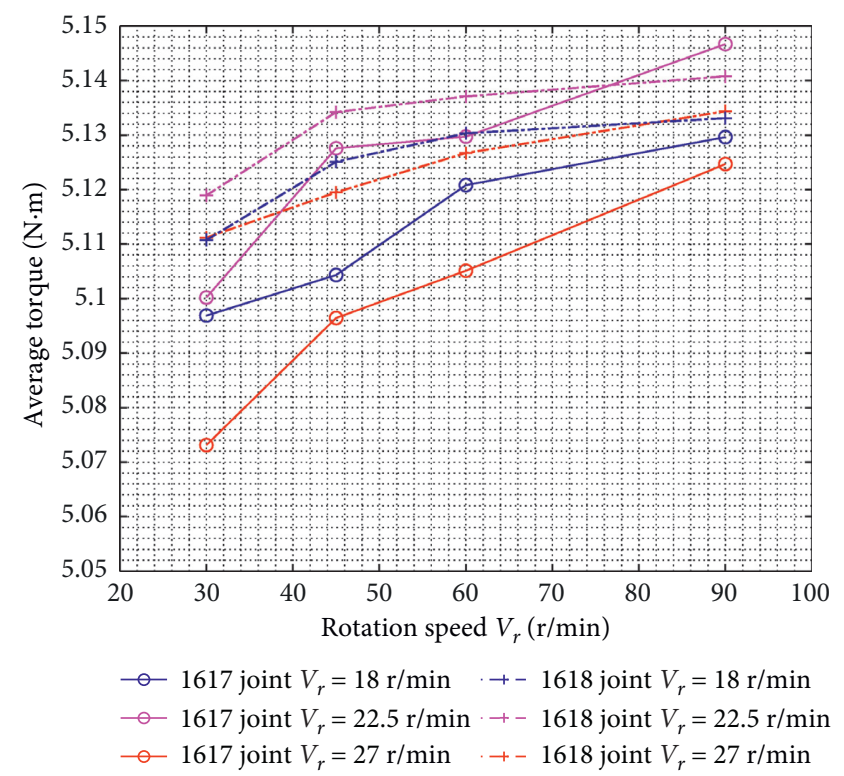

FIgURE 11: Variation of the average of torque changing with rotation speed.

With the increase of rotation speed, the average torque increased gradually, as shown in Figure 11. The effect of the rotation speed on the average torque was more obvious when using the 1617 joint compared with the 1618 joint.

As shown in Figure 12, with the 1617 joint and the 1618 joint, the variation laws of the maximum amplitude of torque fluctuation with rotation speeds are similar at same rotation speed. For penetration rates of 18 and $22.5 \mathrm{~m} / \mathrm{h}$, there was a big difference between the maximum amplitude at rotation speeds of 30 and $45 \mathrm{r} / \mathrm{min}$, while the difference between the maximum amplitude at the rotation speeds of 


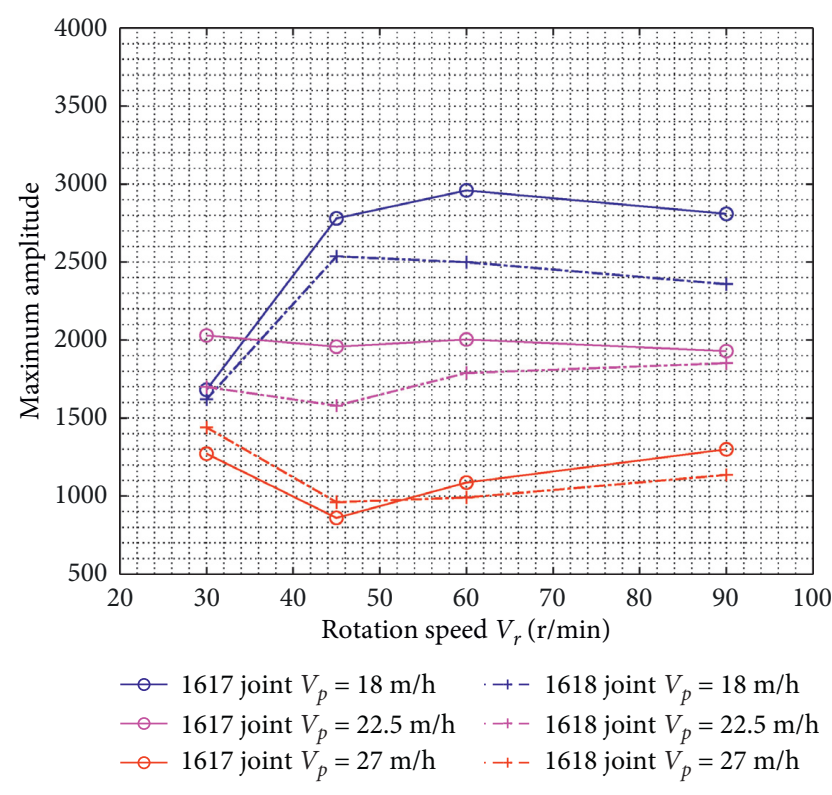

FIGURE 12: Variation of the maximum amplitude of torque fluctuation changing with rotation speed.

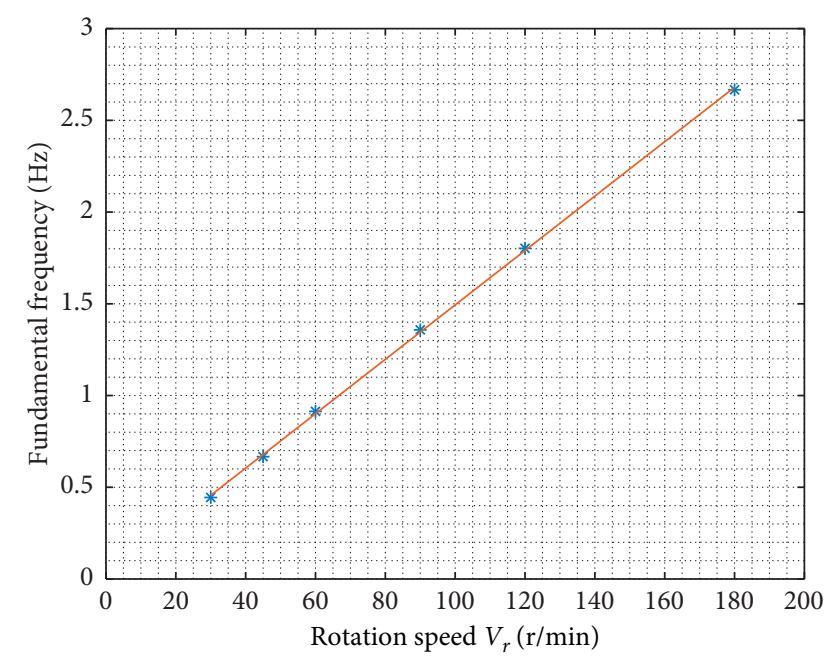

FIGURE 13: Variation of the fundamental frequency of torque under different rotation speeds.

45 to $90 \mathrm{r} / \mathrm{min}$ was small. For the penetration rate of $27 \mathrm{~m} / \mathrm{h}$, the rotation speed had little effect on the maximum amplitude.

Figure 13 shows the fundamental frequency of torque fluctuation at rotation speeds of $30,45,60,90,120$, and $180 \mathrm{r} /$ min. The fundamental frequency increases almost proportionally with the increase of the rotation speed. This phenomenon is consistent with the above theoretical analysis.

\section{Conclusions}

(1) Because of the interaction between the joint with an elliptical outer edge of section and the wellbore wall, low-amplitude forced radial vibration was generated as the drill string rotates, and the effect of the radial vibration on the frictional torque of the rotary drill string was researched in detail.

(2) The average torque and the maximum amplitude of torque fluctuation decreased first and then increased with the increase of the ratio of major radius to minor radius of the joint elliptical section. When the ratio was 1.0625 , the joint exhibited the best frictional torque reduction properties with the minimum average value of torque.

(3) With the increase of rotation speed, the average torque increased gradually. For a penetration rate of $27 \mathrm{~m} / \mathrm{h}$, the rotation speed had a little effect on the maximum amplitude of torque fluctuation. At rotation speeds of 45 and $60 \mathrm{r} / \mathrm{min}$, the difference between the maximum amplitudes was very small at the same penetration rate, and the maximum amplitude of torque fluctuation increased first and then decreased with the increase of penetration rate, and it reached its maximum value at a penetration rate of $22.5 \mathrm{~m} / \mathrm{h}$. Therefore, the penetration rate should be as far away as possible from $22.5 \mathrm{~m} / \mathrm{h}$ in the drilling process.

(4) The fundamental frequency of torque fluctuation was almost linearly related to the rotation speed, which was irrelevant to the penetration rate and the ratio of the major radius to minor radius of the joint.

(5) During drilling, a small number of sand grain easily gradually accumulates at the front end of the drill pipe friction reduction joint, and the formation of sand piles leads to an increase of torque. Consequently, the drilling fluid should have a strong carrying capacity when using the drill pipe friction reduction joint.

\section{Data Availability}

No data were used to support this study.

\section{Additional Points}

SI units are used within the article.

\section{Conflicts of Interest}

The authors declare that there are no conflicts of interest.

\section{Acknowledgments}

This study was supported by the National Natural Science Foundation of China (Grant nos. 51974277 and 51674220).

\section{References}

[1] Z. Li, C. Zhang, and G. Song, "Research advances and debates on tubular mechanics in oil and gas wells," Journal of Petroleum Science \& Engineering, vol. 151, pp. 194-212, 2016.

[2] S. Jiang, W. Jiang, J. Fu, X. Ji, and X. Fu, "Research on extended reach drilling technology and its application in Bohai oilfield," Acta Petrolei Sinica, vol. 24, no. 2, pp. 84-88, 2003. 
[3] Z. Wu and H. Wang, "Field test of solid lubricant being applied to reduce frictional resistance in directional mediumdepth wells," Drilling \& Production Technology, vol. 25, no. 5, pp. $68-70,2002$.

[4] S. Livescu and S. Craig, "A critical review of the coiled tubing friction-reducing technologies in extended-reach wells. Part 2: vibratory tools and tractors," Journal of Petroleum Science and Engineering, vol. 166, pp. 44-54, 2018.

[5] Q. Liao, X. Zhu, S. Liu, C. Shi, J. Du, and H. Liu, "Design and safety analysis of torque-reducing and anti-galling tool of splitting-bearing," Oil Field Equipment, vol. 39, no. 5, pp. 30-32, 2010.

[6] Y. Lu, "Development of torsion reduction tool for extended reach wells," Drilling \& Production Technology, vol. 36, no. 1, pp. 73-75, 2013.

[7] Y. Zhang, H. He, Y. Du, and M. Li, "The development of downhole drag reduction device for coiled tubing," China Petroleum Machinery, vol. 43, no. 7, pp. 36-41, 2015.

[8] P. Wang, H. Ni, R. Wang, Z. Shen, and Z. Li, "Friction reduction research of drill-string longitudinal vibration based on asperity contact," Journal of China University of Petroleum (Edition of Natural Science), vol. 39, no. 1, pp. 88-94, 2015.

[9] S. Ouyang, Y. Ge, L. Cui, and H. Wang, "Design and experimental study on two-way vibration drag reduction tool for coiled tubing drilling," China Petroleum Machinery, vol. 45, no. 11, pp. 18-22, 2017.

[10] B. Li, "Development and application of torsion reduction tool for radial vibration," Inner Mongolia Petrochemical Industry, vol. 44, no. 5, pp. 20-21, 2018.

[11] X. Zhu, H. Tong, Q. Liu, and L. Feng, "New method on calculation of torque and drag based on drilling string system dynamics," Journal of System Simulation, vol. 19, no. 21, pp. 4853-4856, 2007.

[12] Y. Qin, S. Fu, and D. Gao, "A new model for analyzing torque and drag in extended reach wells," Natural Gas Industry, vol. 26, no. 11, pp. 77-79, 2006.

[13] H. Tang, M. Sun, G. Feng, C. Yang, and H. Xu, "A monitoring method for torque \& drag of extended reach wells," Natural Gas Industry, vol. 36, no. 5, pp. 81-86, 2016.

[14] Z. Li, Tubular Mechanics in Oil-Gas Wells and Its Applications, Petroleum Industry Press, Beijing, China, 2008.

[15] J. Fu, G. Li, H. Shi, S. Tian, D. Wang, and Y. Zhang, "Research progress of the downhole vibration antifriction technology," China Petroleum Machinery, vol. 40, no. 10, pp. 6-10, 2012.

[16] N. Wicks, J. A. Pabon, and A. S. Zheng, "Modeling and field trials of the effective tractoring force of axial vibration tools," in Proceedings of SPE Deepwater Drilling and Completions Conference, pp. 10-11, Galveston, TX, USA, September 2014.

[17] C. Yi, G. Li, and H. Fan, "The design and experimentation of vibrational friction-reducing generator for down hole drilling," Oil Field Equipment, vol. 32, no. 6, pp. 42-44, 2003.

[18] P. B. Steven, B. Franklin, and A. Aref, "Drilling performance improvement in gas shale plays using a novel drilling agitator device," in Proceedings of SPE North American Unconventional Gas Conference and Exhibition, pp. 14-16, Woodlands, TX, USA, June 2011.

[19] J. P. McCarthy, B. Stanes, J. E. Rebellon et al., "A step change in drilling efficiency: quantifying the effects of adding an axial oscillation tool within challenging wellbore environments," in Proceedings of SPE/IADC Drilling Conference and Exhibition, pp. 17-19, Amsterdam, Netherlands, March 2009.

[20] K. R. Newman, T. G. Burnett, J. C. Pursell, and G. Ouahab, "Modeling the affect of a downhole vibrator," in Proceedings of the SPE/ICoTA Coiled Tubing \& Well Intervention Conference and Exhibition, p. 31, Woodlands, TX, USA, March-April 2009.

[21] J. J. Kolle, A. R. Theimer, A. W. Fraser, and S. Fletcher, "Predicting the extended reach capabilities of a water-hammer tool with variable bypass control," in Proceedings of the SPE/ICoTA Coiled Tubing and Well Intervention Conference and Exhibition, pp. 22-23, Houston, TX, USA, March 2016.

[22] Y. Su, X. Dou, and J. Wang, "Antifriction tool and its application," Oil Drilling \& Production Technology, vol. 27, no. 2, pp. 78-80, 2005.

[23] H. Zhang, Z. Guan, K. Ke, and Y. Dou, "The impact of lateral vibration on friction of drill string in horizontal wells," $P e$ troleum Drilling Techniques, vol. 43, no. 3, pp. 61-64, 2015.

[24] W. Ren, Experimental Research and Structural Optimization Design of Friction Reducing and Torsion Reducing Tools, Yanshan University, Qinhuangdao, China, 2018.

[25] Z. Li, C. Zhang, W. Ren, and G. Song, "An experimental device to test the performance of tools with reducing friction and torsion in oil-gas wells," China Patent No: ZL 201710036667.0, 2017.

[26] C. Han and T. Yan, "Lateral drill string vibration in horizontal holes," China Petroleum Machinery, vol. 33, no. 1, pp. 8-10, 2005. 